\title{
THE PHYSICAL DEVELOPMENT OF MONGOLS
}

\author{
BY \\ G. DUTTON \\ From St. Lawrence's Hospital, Caterham
}

(RECEIVED FOR PUBLICATION JULY 7,1958 )

Because it is a well differentiated and common form of mental defect, mongolism has been exhaustively studied. Most of the studies, however, have been directed at the possible aetiology of this condition. This paper is not concerned with aetiological problems but is a discussion of two purely physical findings in mongol boys, height and skeletal age. Some findings in adult male mongols have been included for reasons that will be apparent.

\section{Material}

The material is derived from the wards of a large hospital dealing with mental defectives. All cases are typical mongols, in whom diagnosis is without question, and cases that require close study to determine that they are mongols have been excluded since the value of this work was thought to depend on the homogeneity of the material. Both adult and child male mongols were selected on the known physical characteristics: eyes, epicanthus, tongue, etc. The survey has been limited to male mongols because the bed allocation at the hospital is such that it was not possible to obtain a worthwhile group of female mongol children.

\section{Methods}

Height. This was measured in the erect position in bare feet with a conventional stadiometer. The 'standard erect posture' of Krogman (1950) was used throughout the measurements. The figures for full height so obtained have been used as the raw figures and also converted to a height age by reference to the tables for normal children of Sutcliffe and Canham (1950). These tables have been chosen because they are comparatively recent, referring to a survey in 1947, and also because they were obtained on English children.

The height age so obtained has been converted to a percentage by dividing by the life age and multiplying by 100 . This has the advantage of allowing comparisons to be made irrespective of age (Talbot, Sobel, Burke, Lindemann and Kaufman, 1947), and also of a direct comparison with skeletal age.

Skeletal Maturation. The skeletal age has been assessed by the inspectional method from a radiograph of one hand and wrist, comparisons being made with the standards in the atlas of Greulich and Pyle (1950). Each film was assessed by me, blind, on three separate occasions, the mean being taken as the skeletal age. The raw figures so obtained have been used for comparison with the mean and standard deviations given by Greulich and Pyle.

The figure for skeletal age has also been accorded the same treatment as that for the height age and a developmental quotient obtained for the purpose of comparison.

The data from these investigations have been used throughout in a cross-sectional manner although they have been obtained from both cross-sectional and longitudinal surveys carried out on the children at this hospital.

\section{Results}

These are given diagramatically in the following figures.

Height. Fig. 1 is a comparison between the height of mongol boys in inches and their life age in years. The mean for normal boys and two standard deviations below the mean (London County Council, 1955) are given.

The figure demonstrates how far behind the normal in height the mongol boy is, for no case in this series falls within the normal range and the larger number of them are well below minus two standard deviations.

When height quotients are considered (height quotient is height age multiplied by 100 and divided by life age) it is found that the peak incidence is at 


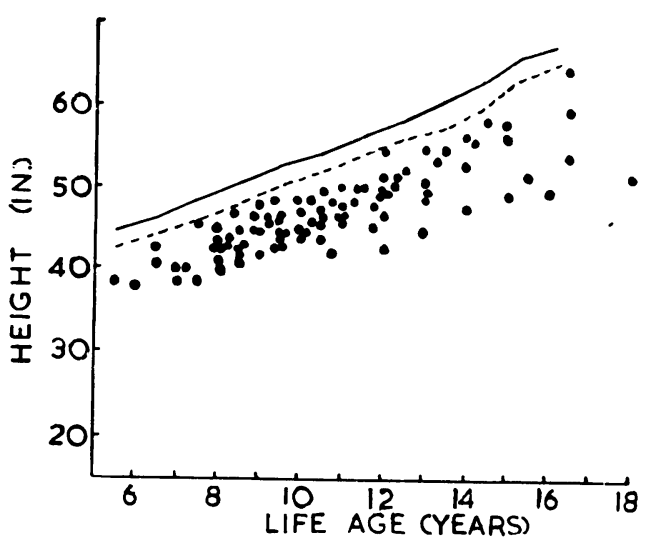

Fig. 1.-The relation of the heights of mongol boys to their life age. $=$ mean for normal boys; $----=2 S$.D. below the mean (Mean and S.D. from London County Council, 1955).

about the $60 \%$ level. This is demonstrated in Fig. 2. The mean height quotient of 78 assessments was found to be $67.8 \%$. The normal range quoted by Talbot et al. (1947) for height quotients is 80 $120 \%$.

Skeletal Development. Skeletal age compared with life age is shown in Fig. 3. The mean for normal boys and two standard deviations above and below the mean (Greulich and Pyle, 1950) are included for purposes of comparison.

This picture is very different from that obtained when height was being considered, for now we find that mongol boys are predominantly normal as far as their skeletal maturation is concerned.

Fig. 4 demonstrates the frequency of the developmental quotients as far as the skeletons of mongol boys are concerned. This shows that the peak incidence is around the $100 \%$ level. In fact the arithmetic mean for the skeletal quotient on these cases was found to be $94.5 \%$. This accentuates the difference between the height and the skeletal development and for comparison both developmental quotients are given in Table 1.

TABle 1

MEAN DEVELOPMENTAL QUOTIENTS OF MONGOL BOYS

\begin{tabular}{c|c}
\hline $\begin{array}{c}\text { Height Age } \\
\text { Life Age }\end{array}$ & $\begin{array}{c}\text { Bone Age } \\
\text { Life Age }\end{array} 100$ \\
\hline $67 \cdot 8 \%$ & $94 \cdot 5 \%$ \\
\hline
\end{tabular}

Mongols appear to present a failure of linear growth without a concomitant failure of skeletal development. It was necessary to examine the

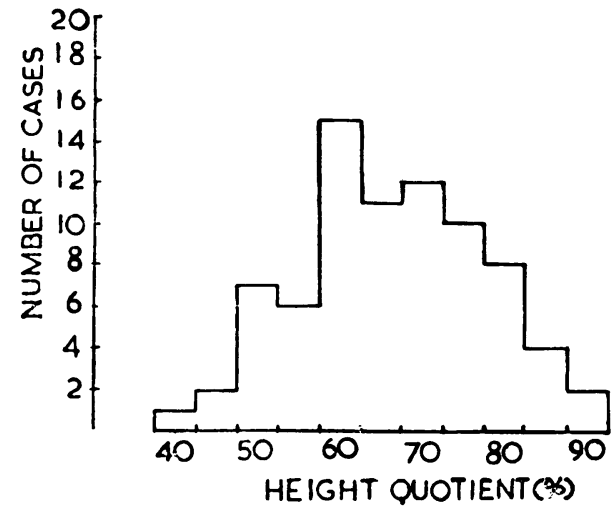

FIG. 2.-The distribution of the height quotient in mongol boys. (Height quotient is height age divided by life age and multiplied by 100.)

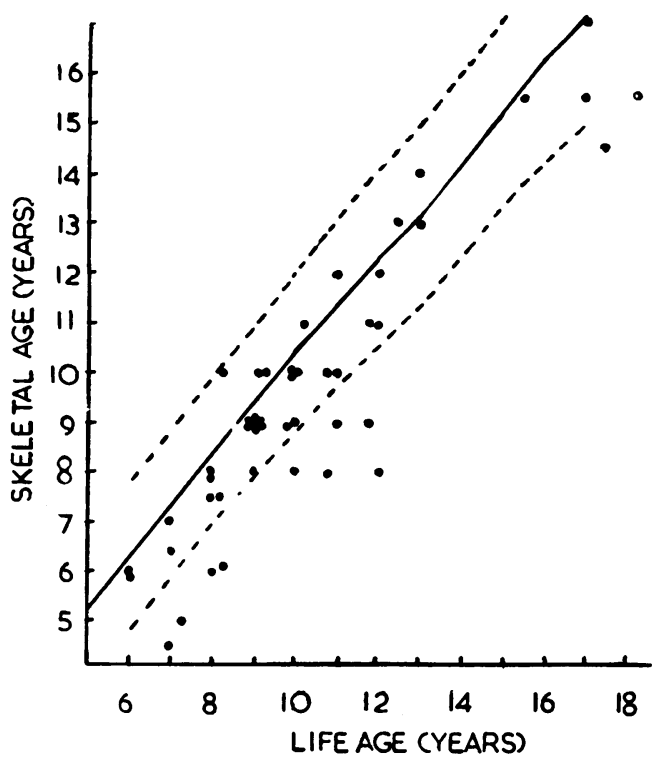

FIG. 3.-Skeletal age compared with life age in mongol boys. $=$ mean for normal boys; $----=2$ S.D. above and below the mean (from Greulich and Pyle, 1950).

failure in linear growth more closely from a developmental angle. Bayley and Pinneau (1952) from a longitudinal study of the growth of a group of children have produced figures for the mean and standard deviations of percentage of mature height reached for the life age. But to compare the height of mongols with that of normal adults seemed unreasonable and it is fairer to compare the growing mongol boy with adult male mongols. It was therefore necessary to determine what was the mean 


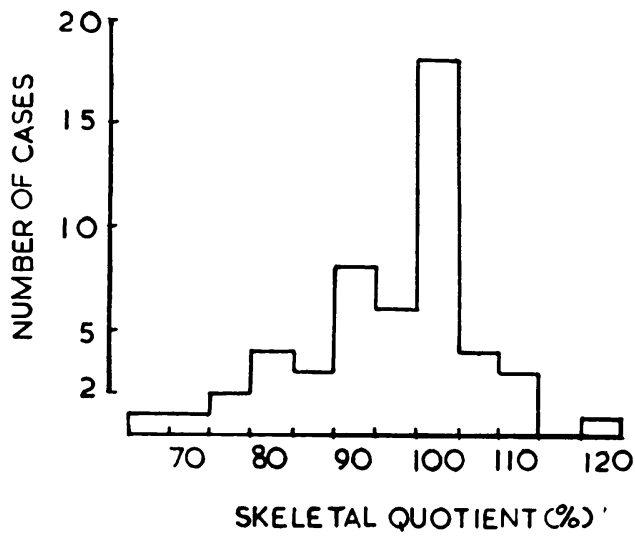

FIG. 4.-The distribution of skeletal quotients in mongol boys. (Skeletal quotient is skeletal age divided by life age and multiplied by 100.)

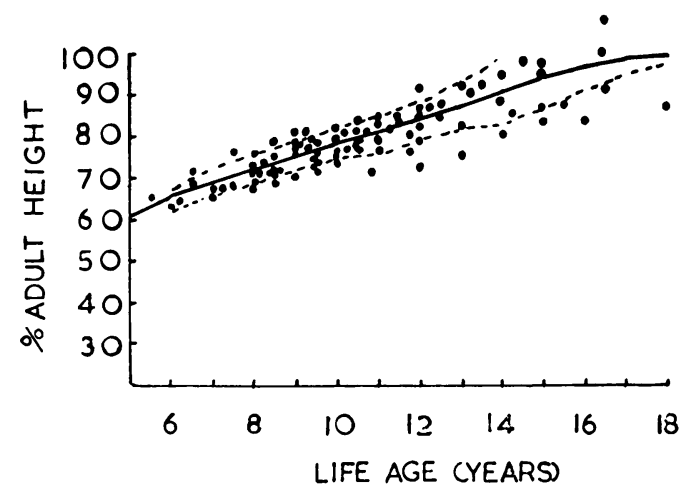

Fig. 6.-Percentage of adult height obtained for life age, adult height for mongols being taken as $59 \cdot 0$ in. - - mean for normal children; - - - $=2$ S.D. above and below the mean (from Bayley and Pinneau, 1952).

adult male mongol height and this has been done in 42 male mongols over 19 years of age under the same circumstances and with the same stadiometer as has been used for the children. The results of this assessment are given in Fig. 5, which shows the peak incidence occurring at $59 \cdot 0 \mathrm{in}$. This is actually the arithmetic mean of the group. This result compares with the figures quoted by Benda (1949), in which the mean height of 12 male mongols over 19 years is 58.8 in., whilst the mean obtained from the figures of Brousseau (1928) on 22 mongol men is 57.5 in. For the purpose of comparison the figure of $59.0 \mathrm{in}$. as the adult male mongol height has been used.

Fig. 6 has been derived using the adult height of mongols as above and converting the actual height

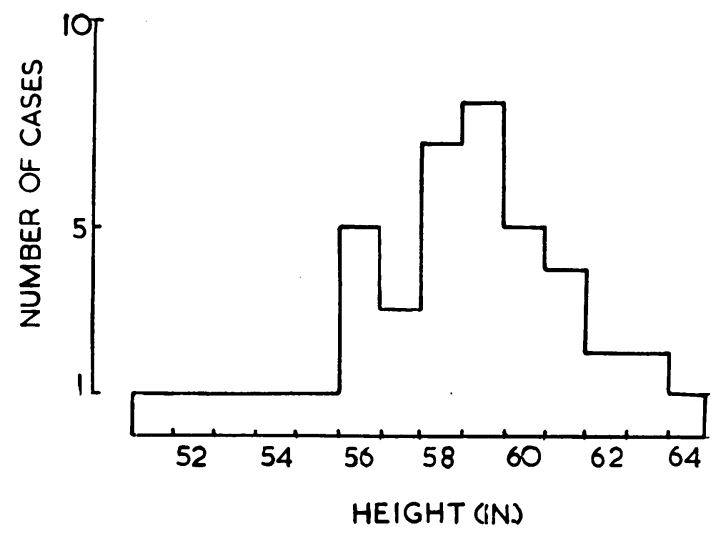

FIG. 5.-The distribution of heights of adult male mongols.

to a percentage of this. The percentage so obtained has been plotted against the life age. The normal and two standard deviations above and below the mean have been given and are taken from the work of Bayley and Pinneau (1952). From this graph it is seen that the height of mongol children develops towards their adult height in a similar manner to normal children.

\section{Discussion}

It is often stated that mongols are examples of the unfinished child. Kirman (1957) says 'Mongolism is essentially a picture of delayed physical and mental development', and Penrose (1954) 'The clinical and pathological signs of mongolism can be summarized by saying that almost all of them are indications of retarded development'. There is, however, one aspect of their development that has been shown in this paper to be essentially normal: the maturation of the skeleton.

The maturation of the skeleton has often been referred to in works on mongolism but there is quite a discrepancy in the results. Brousseau (1928) says that there is retarded development but admits later that opinions differ and points out that whilst there may be delay in ossification in mongolism it is not so marked as in cretinism. Engler (1949) is of the opinion that there is no appreciable delay in the appearance of centres of ossification and suggests that this may be used to differentiate mongolism from cretinism. Kirman (1957) makes no direct reference to the skeletal age at all. Benda (1949) does not give any details but states that the appearance of ossification centres is frequently retarded and resembles the picture of cretinism. Hefke (1940) in his paper on the anomalies to be found radiographically in the hands of mongols has 
reviewed the literature and quotes very divergent opinions as regards the skeletal age. He goes on to describe his findings in 72 mongols between the ages of 2 months and 15 years. He found osseous development was normal in $79 \%$, advanced in $14 \%$ and delayed in $7 \%$ but he does not say what constitutes normality in relation to standard deviations in his series. In my series, and assuming that cases falling between plus and minus two standard deviations are normal, I found no cases to be hypermature and $20.8 \%$ were delayed as regards their skeletal maturity. In mongols, then, from this series it can be said that nearly $80 \%$ have a normally developing skeletal maturation. At one time it was thought that the short stature of adult mongols was due to a hypermature skeleton that had resulted in the premature fusion of epiphyses, but this hypothesis is not tenable on the evidence of skeletal maturation presented here.

When height alone is considered mongol children are found to be very retarded in linear growth, no cases coming up to the normal expectation. This has been reported before but when one considers the development of linear growth towards normal adult mongol height the maturation is surprisingly normal. A comparison between the height and expected height for age shown in Fig. 1 and Fig. 6 showing the percentage of adult height obtained for age shows this difference very well. From this it seems fair to say that in mongol boys, although the absolute height is depressed when compared with that of normal boys, the development of height is normal for mongols and that this is yet another aspect of maturation which proceeds normally.

To differentiate between growth and development is important since these two aspects are under different control. The maturation of the skeleton is influenced by the thyroid; in cretinism there is a marked delay in skeletal maturation and the administration of an active thyroid principal brings about a remarkable skeletal advancement (Zondek, Kaatz, Leszynsky, Margoliash and Stein, 1958).

Linear growth, on the other hand, is under the control of the anterior pituitary growth hormone and this has little influence on maturation. There are, of course, other factors which are integrated in the hormonal control of growth (Hubble, 1957), but as regards the differentiation between growth and development the growth factor and the thyroid hormone appear to be the prime movers. Even so it would be incorrect to isolate these two factors since it is necessary for other hormones to be present as well as an adequate supply of the necessary building materials for normal growth and development to occur.
Since the problem is one of growth failure it is permissible to look at the problem from the aspect of protein metabolism and, if one accepts the equations given by Hubble, the two possibilities are a diminution of the anabolic hormones (the left hand side of the equation) or an increase in the catabolic hormones (the right hand side of the equation). In the pre-steroid phase of growth in mongols I have found the daily excretion of total 17-ketosteroids and 17-ketogenic steroids to be essentially normal and this would appear to exonerate the adrenals. These findings, which are as yet unpublished, are in agreement with the results of Bixby and Benda (1944) who found that the adrenal androgens were normal in mongols but that there was a failure of testicular androgens.

The evidence presented here supports the contention that in mongols thyroid function is normal and this is in agreement with the findings of Sobel, Strazzulla, Sherman, Elkan, Morgenstern, Marius and Meisel (1958) who were unable to detect a significant difference in the levels of protein-bound iodine in mongols and controls. Benda, on the other hand, considers that mongols show an increase in blood cholesterol and a low B.M.R. Sobel et al. (1958) did not confirm the alteration in the level of cholesterol.

When carbohydrate metabolism is considered as an indirect method of assessing insulin secretion there is a difference of opinion between Sobel et al. (1958) and Benda (1949), the former finding normal levels of fasting blood sugar and the latter an increased sugar tolerance with flat curves and an inability of adrenalin to raise the blood sugar significantly. The evidence offered by Benda does not suggest an abnormality of insulin metabolism but rather a primary abnormality of glycogen storage and release by the liver.

Returning then to the equations for hormonal growth, during the pre-steroid phase in mongols, three of the principal protein anabolizers and the principal catabolic hormone are exonerated and all that is left is the growth factor on the anabolic side of the equation. This hormone is not as easily assessed as the others, and in fact there is no direct assay available, but the evidence suggests that it is this aspect of the endocrine system that is at fault in mongols if the disorder is of a hormonal nature.

\section{Summary}

Two aspects of the physical development of mongol boys are discussed, height and skeletal maturation. It is shown that skeletal maturation is normal in $80 \%$ of cases and that mongols although 
deficient in linear growth mature normally towards mongol adulthood.

The possible significance of these findings is discussed in relation to endocrine imbalance.

I wish to express my thanks to Dr. J. M. Crawford, Physician Superintendent at Botleys Park Hospital, Chertsey, for his encouragement and for his permission to undertake the survey. I am also grateful to the nursing staff and patients for their willing co-operation and to Mr. E. Comer, the hospital radiographer, who took all the radiographs.

\section{REFERENCES}

Bayley, N. and Pinneau, S. R. (1952). J. Pediat., 40, 423. Benda, C. E. (1949). Mongolism and Cretinism, 2nd ed. Grune and Stratton, New York.

Bixby, E. M. and Benda, C. E. (1944). Amer. J. ment. Defic., 49, 138.
Brousseau, K. (1928). Mongolism: A Study of the Physical and Mental Characteristics of Mongolian Imbeciles. Williams and Milkins, Baltimore

Wilkins, Baltimore
Engler, M. (1949). Mongolism. J. Wright, Bristol.

Greulich, W. W. and Pyle, S. I. (1950). Radiographic Atlas of Skeletal Development of the Hand and Wrist. Stanford, California.

Hefke, H. W. (1940). Amer. J. Dis. Child., 60, 1319.

Hubble, D. (i957) Brit. med. J. 1, 601.

Kirman, B. H. (1957). In L. T. Hilliard and B. H. Kirman's Mental Deficiency, p. 308 . Churchill, London.

Krogman, W. M. (1950). A Handbook of the Measurement and Interpretation of Height and Weight in the Growing Child. Monogr. Society for Research in Child Development. Serial No. 48, vol. 13, no 3 .

London County Council (1955). Report on the Heights and Weights of School Pupils in the County of London in 1954.

Penrose, L. S. (1954). The Biology of Mental Defect, 2nd ed Sidgwick and Jackson, London.

Sobel, A. E., Strazzulla, M., Sherman, B. S., Elkan, B., Morgenstern S. W., Marius, N. and Meisel, A. (1958). Amer. J. ment. Defic., 62, 642.

Sutcliffe, A. and Canham, J. W. (1950). The Heights and Weights of Boys and Girls. Murray, London.

Talbot, N. B., Sobel, E. H., Burke, B. S., Lindemann, E. K. and Kaufman, S. B. (1947). New Engl. J. Med., 236, 783.

Zondek, H., Kaatz, A., Leszynsky, H. E., Margoliash, E. and Stein, J. A.'(1958). Brit. med. J., 1, 546 . 